\title{
Importance of orthodontic intervention of the Class III malocclusion in mixed dentition
}

\author{
Dennyson Brito Holder da Silva ${ }^{1}$ Ariane Salgado Gonzaga²
}

DOI: https://doi.org/10.1590/2177-6709.25.5.057-065.bbo

Introduction: Supervising the development of occlusion, managing problems during the transition from mixed to permanent dentition, as well as controlling environmental factors that contribute to establishing malocclusion, are important actions to achieve a Class I occlusion with facial balance. Among these problems, the malocclusions associated with dysfunctions such as mouth breathing or obstructive sleep apnea syndrome (OSAS), atypical swallowing and abnormal tongue position, open bites, crossbites and maxillomandibular discrepancies, and especially the Class III malocclusion can be listed. Objective: The purpose of this article is to present and discuss the main aspects relevant to the benefits of performing the treatment of Class III malocclusion in patients with growth.

Keywords: Interceptive orthodontics. Corrective orthodontics. Malocclusion.

\begin{abstract}
Introdução: A supervisão do desenvolvimento da oclusão e o gerenciamento de problemas durante a transição da dentição mista para a permanente, bem como o controle de fatores ambientais que contribuem para estabelecer a má oclusão, são importantes ações para se obter uma oclusão de Classe I com equilíbrio facial. Entre esses problemas, pode-se considerar más oclusões associadas às disfunções como respiração bucal ou síndrome da apneia obstrutiva do sono (SAOS), deglutição atípica, posição anormal da língua, mordidas abertas e mordidas cruzadas e discrepâncias maxilomandibulares, especialmente, a má oclusão de Classe III. Objetivo: O objetivo do presente artigo é apresentar e discutir os principais aspectos pertinentes aos benefícios de se realizar o tratamento da má oclusão de Classe III em pacientes com crescimento.
\end{abstract}

Palavras-chave: Ortodontia interceptora. Ortodontia corretiva. Má oclusão.

\section{INTRODUCTION}

Supervising the development of occlusion, managing problems during the transition from mixed to permanent dentition, as well as controlling environmental factors that contribute to establishing malocclusion, are important actions to achieve Class I occlusion with facial balance, which often does not occur naturally without interceptive orthodontic treatment. Orthodontic approaches may be related to different categories of problems, such as a malocclusion in development, in which it may be necessary to intervene to reduce or interrupt the unfavorable

${ }^{1}$ Academia Norte-Rio-Grandense de Odontologia (Natal/RN, Brasil).

${ }^{2}$ Universidade Federal do Rio Grande do Norte, Departamento de Odontologia (Natal/RN, Brasil).

» The authors report no commercial, proprietary or financial interest in the products or companies described in this article.

" Patients displayed in this article previously approved the use of their facial and intraoral photographs. change; ${ }^{1}$ or a dentition whose normal development can be interrupted by some local etiological factor, which requires treatment to maintain or restore the appropriate development. ${ }^{2}$

Some of the most relevant objectives of supervising the development of occlusion are to properly manage the growth potential in order to intercept skeletal imbalances, eliminate functional deviations, improve self-esteem, minimize trauma and prevent periodontal problems. ${ }^{3}$ The possible advantages of the early intervention are the emotional satisfaction of the child, the growth potential available at this stage
How to cite: Silva DBH, Gonzaga AS. Importance of orthodontic intervention of the Class III malocclusion in mixed dentition. Dental Press J Orthod. 2020 Sept-Oct;25(5):57-65.

DOI: https://doi.org/10.1590/2177-6709.25.5.057-065.bbo

Submitted: July 20, 2020 - Revised and accepted: July 30, 2020

Contact address: Dennyson Brito Holder da Silva

E-mail: dennysonbholder@gmail.com 
of development, greater collaboration with treatment, the possibility of a more simplified second phase and the possible reduction of extractions in the corrective phase of treatment. Disadvantages also exist, such as inefficiency, longer treatment time, immaturity of the patient, inefficient oral hygiene, inability to care for the devices and cost.

The ideal age to treat malocclusions in growing patients has been a widely discussed and controversial topic. One of the most important debates is to stop the development of problems with early treatment or to delay therapy. Among these problems, the malocclusions associated with disorders such as mouth breathing or obstructive sleep apnea syndrome (OSAS), atypical swallowing and abnormal tongue position, open bites and crossbites, and maxillomandibular discrepancies, and especially the Class III malocclusion can be listed.

Class III malocclusion is a condition that can be classified as dentoalveolar, skeletal or functional, and its etiology will determine the diagnosis and prognosis of treatment. ${ }^{4}$ This malocclusion must be intercepted early, preferably during the deciduous dentition phase, since Class III tends to exacerbate itself during growth, especially during adolescence. ${ }^{4-6}$ The sooner treatment is started, the greater the compensatory orthopedic effects of the inevitable orthodontic discrepancies, which can often prevent need for orthognathic surgery at the end of growth. In addition, the early treatment of Class III brings psychological benefits, due to the improvement of facial aesthetics that also implies in the improvement of self-esteem..$^{5,6}$

Long-term studies of early treated Class III malocclusions reveal that the results of the treatment are stable, with visible improvement in facial profile, occlusion and masticatory functions. ${ }^{4,6}$ Maxillary protraction therapy with a facemask is the most common treatment for patients with skeletal Class III due to maxillary retrusion, as it stimulates maxillary advancement and assists in the control of mandibular development. ${ }^{7}$ As this type of treatment must be started early, the anchorage is performed on permanent and/or deciduous teeth, stimulating the movement of the maxilla forward, rotating the mandible down and back, and decreasing the rotation of the palatal plane. There is also the projection of the upper incisors, mesialization and extrusion of the upper molars and the retroinclination of the lower incisors. ${ }^{4-7}$
In addition to the anteroposterior skeletal discrepancy, it is common to find other malocclusions associated with Class III due to maxillary hypoplasia, such as posterior crossbite and anterior open bite. Once the muscular balance is compromised by the negative overjet, habits such as the anteriorization of the tongue on swallowing and phonation are perpetuated during the child's development, changing the muscle tone, the posture at rest, and consequently establishing the anterior open bite..$^{4,6,8,9}$ It is for this reason that the interception of oral habits and multiprofessional treatment is essential for the stability of the results obtained with orthopedic and orthodontic therapy. ${ }^{4,8,9}$

Therefore, the objective of this article is to present and discuss the main relevant aspects of the benefits of carrying out the supervision of the development of the occlusion, in addition to describing the interceptor and corrective orthopedic and corrective treatment of a patient with growing Class III malocclusion (case report presented to the Brazilian Board of Orthodontics and Facial Orthopedics).

\section{CASE REPORT}

Male patient, at the end of the first transitional period of mixed dentition, aged 8 years and 4 months, with good general health and without carious lesions or periodontal problems. During the initial consultation, the patient reported as the main complaint "the lower part is crossed and developed", in addition to the practice of parafunctional habits.

Upon extraoral examination, the patient's face revealed typical characteristics of Class III malocclusion, with a deficiency of the middle third of the face, without zygomatic projection, showing the sclera in the lower part of the iris and active lip sealing. In frontal view, there was a slight facial asymmetry with mandibular deviation to the right, while in lateral view it showed a concave profile, with a chin-neck line apparently adequate to the face size (Fig 1). During the anamnesis and initial examination, the parafunctional habits of lingual interposition in phonation, adapted swallowing and tongue hypotonia were found.

The intraoral analysis showed an Angle Class I dental relationship, maxillary hypoplasia, bilateral posterior crossbite, anterior crossbite with a $-6 \mathrm{~mm}$ 
overjet, anterior open bite of $7 \mathrm{~mm}$ and inverted lower Spee curve. In addition, there was a severe lack of space of $-8 \mathrm{~mm}$ in the upper arch to the lateral incisors irruption, biprotrusion and diastema between the upper central incisors. Despite the slight mandibular deviation to the right and the existence of diastemas, the upper and lower midlines were coincident (Fig 2).

In the initial panoramic radiographic examination, it was observed the impaction of upper lateral incisors, with their roots in the developmental stage 8 of Nolla. The lack of space for the irruption of upper canines was also noticed, while the other permanent teeth had normal development and positioning (Fig 3). The lateral teleradiography of the face showed excessive vestibular inclination of the upper and lower incisors, maxillary hypoplasia, mandible with adequate size and position, and relatively short cranial base (Fig 4).
Steiner's cephalometric analysis revealed a growth tendency of Class III $\left(\mathrm{SNA}=80^{\circ}, \mathrm{SNB}=80^{\circ}\right.$ and $\left.\mathrm{ANB}=0^{\circ}\right)$, while Wits ${ }^{10}$ analysis $(-4 \mathrm{~mm})$ showed a real Class III. The patient had a horizontal growth pattern $\left(\mathrm{Y}\right.$ axis $=54^{\circ}$, $\mathrm{FMA}=22^{\circ}$ and $\mathrm{SN} . \mathrm{GoGn}=31^{\circ}$ ) and dental biprotrusion confirmed by measurements $1 . \mathrm{NA}=29^{\circ}, 1-\mathrm{NA}=6 \mathrm{~mm}$, 1. $\mathrm{NB}=35^{\circ}, 1-\mathrm{NB}=8 \mathrm{~mm}$ and $\underline{1} \cdot \overline{1}=114^{\circ}$ (Table 1$)$.

\section{TREATMENT PLAN}

A two-stage treatment was suggested due to the type of malocclusion. The first stage was the orthopedic treatment with palatal disjunction, maxillary protraction and interception of the parafunctional habit; and the second, the corrective orthodontic treatment with fixed appliances.

For the first phase of treatment, a modified Haas appliance was planned, with vestibular hooks, anchored on the deciduous second molars with a protocol of activation twice a day (morning and night),
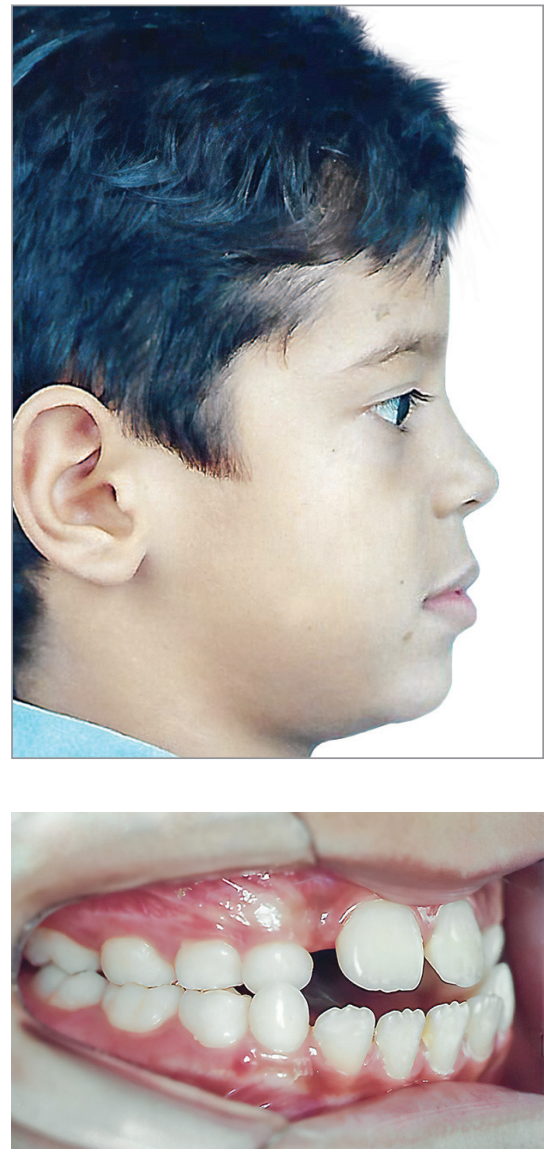

Figure 1 - Facial and intraoral initial photographs.
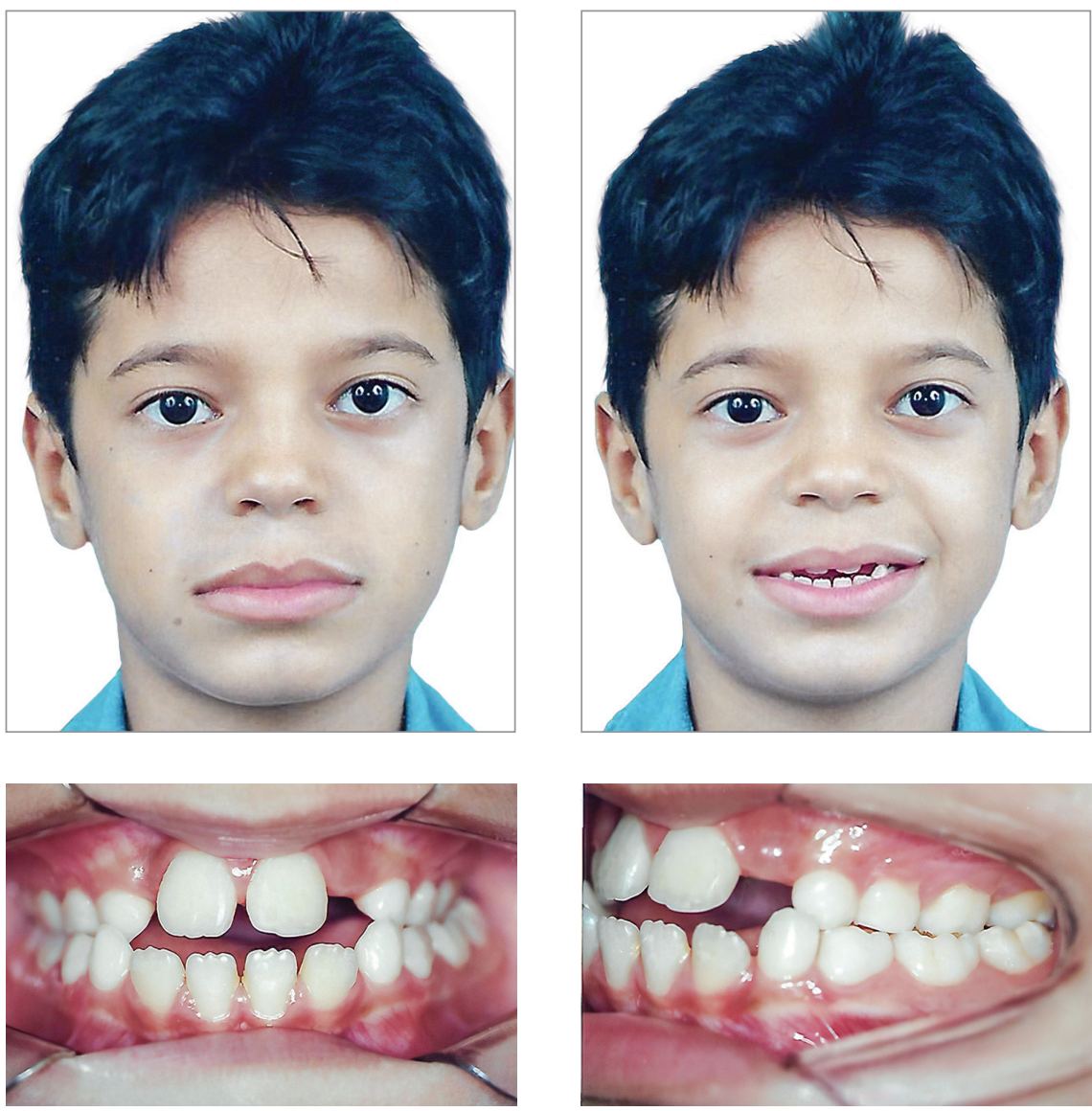

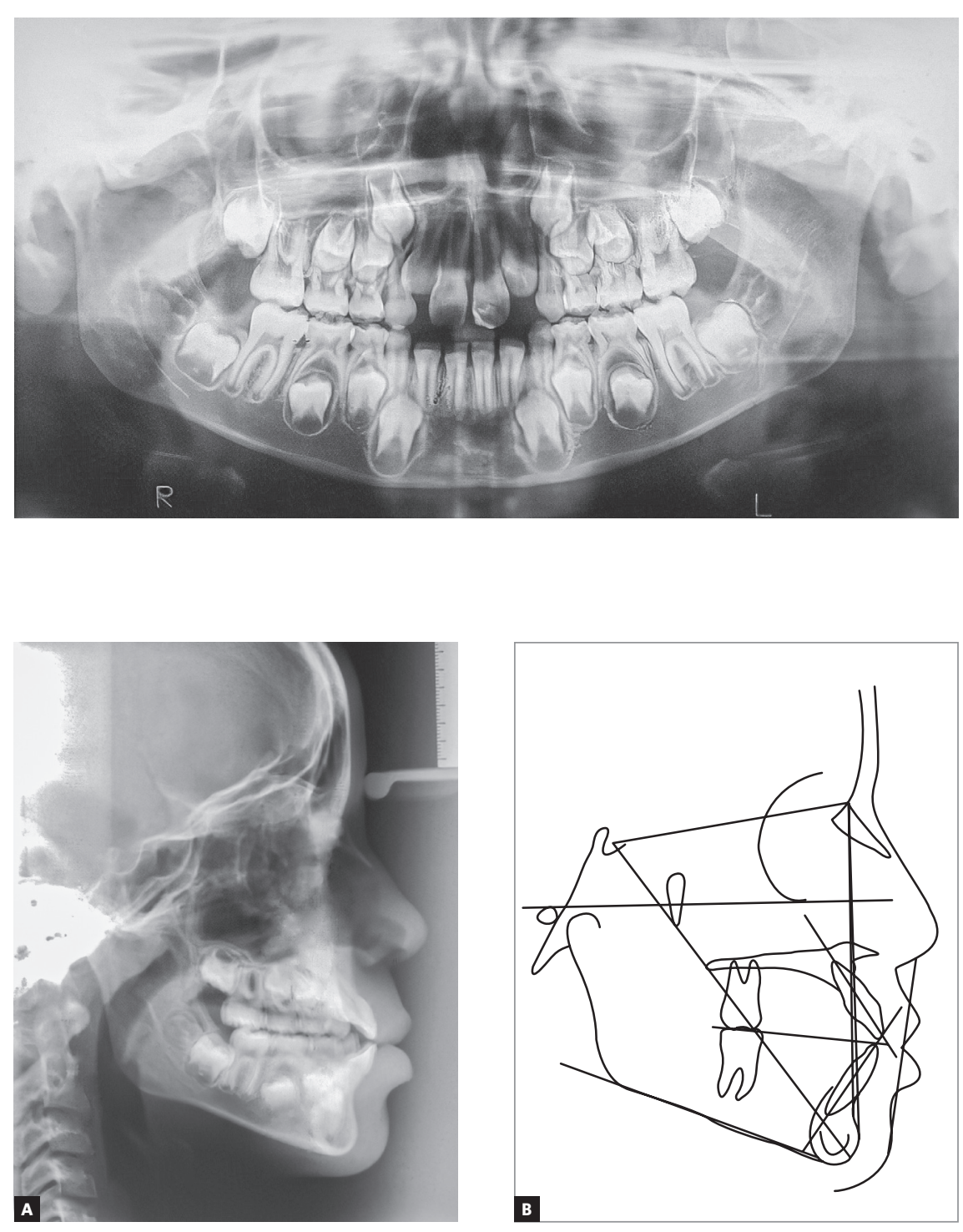

Figure 2 - Initial panoramic radiograph.

Figure 3 - Initial cephalometric radiograph (A) and cephalometric tracing (B). for 10 days or until overcorrection of the posterior crossbite. Petit's facemask was installed, with $500 \mathrm{gF}$ on each side and daily use of at least 16 hours. A lingual arch with spurs was also placed to intercept the tongue interposition habit. The maxillary protraction mechanics was actively conducted for approximately one year, a period necessary for the overcorrection of the anteroposterior discrepancy, and after this period, another six months of night use to preserve the results obtained. Spurs welded to the lingual arch were maintained during the second phase of treatment, until the correction of the anterior open bite, at which point the patient was referred for speech therapy.
The second phase of the treatment consisted of the corrective orthodontics, with the use of a Roth prescription $(0.022 \times 0.028$-in) fixed metal appliance. A $4 \times 2$ mechanics was adopted in order to correct the Spee curve of the lower arch. After the initial alignment and leveling, Class III intermaxillary elastic mechanics (3/16-in, medium strength) and intercuspation mechanics with $1 / 8$-in medium strength elastics in a $0.019 \times 0.025$-in braided stainless steel wire were applied. A removable wraparound retainer was planed for the upper arch, and a fixed $3 \times 3$ lingual bar, made with 0.018 -in twisted flex wire, and maintained indefinitely for the lower arch. 


\section{RESULTS}

At the end of the treatment, the initial objectives were achieved, with a visible improvement in the facial profile and anteroposterior relationship of the face (Fig 5). A Class I of molars and canines was obtained, correction of the Spee curve, correct transversal relationship between the arches and adequate overbite and overjet (Fig 6). With the association of orthopedic and orthodontic mechanics it was possible to redirect the craniofacial growth, obtaining a Skeletal Class I relationship (ANB $=+2^{\circ}$ and Wits $=+1 \mathrm{~mm}$ ) (Table 1, Figs 7, 8, 9 and 10). Thus, adequate functional guides and correct posture and tonus of the tongue were established.
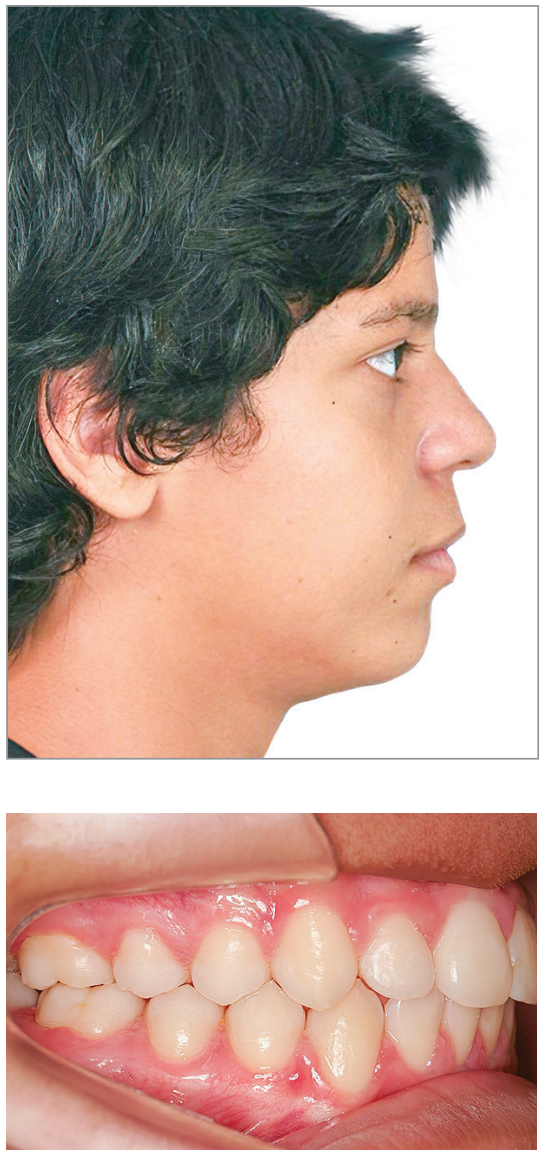

Figure 4 - Facial and intraoral final photographs
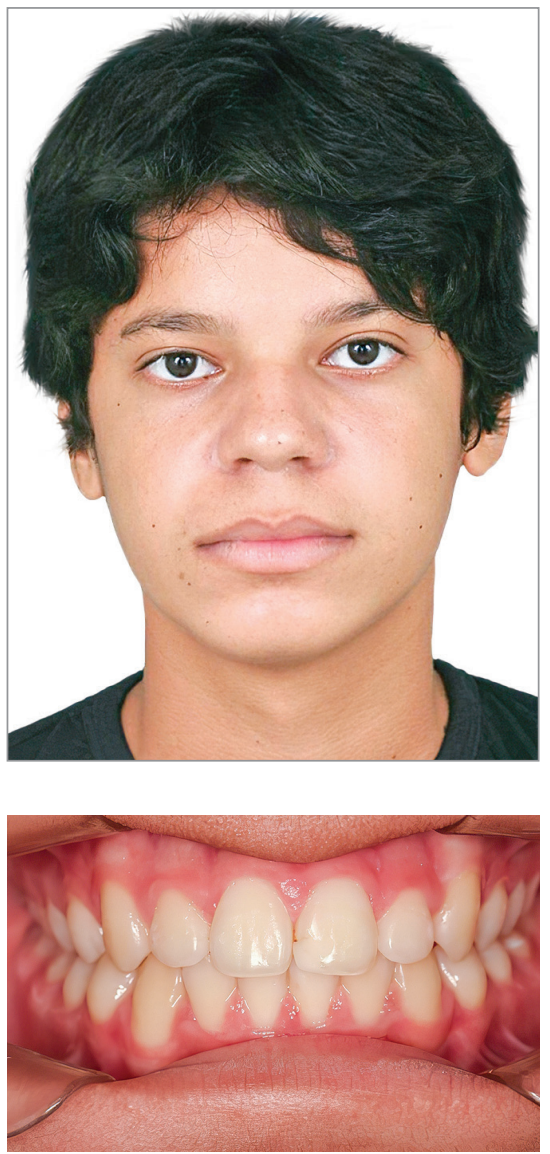
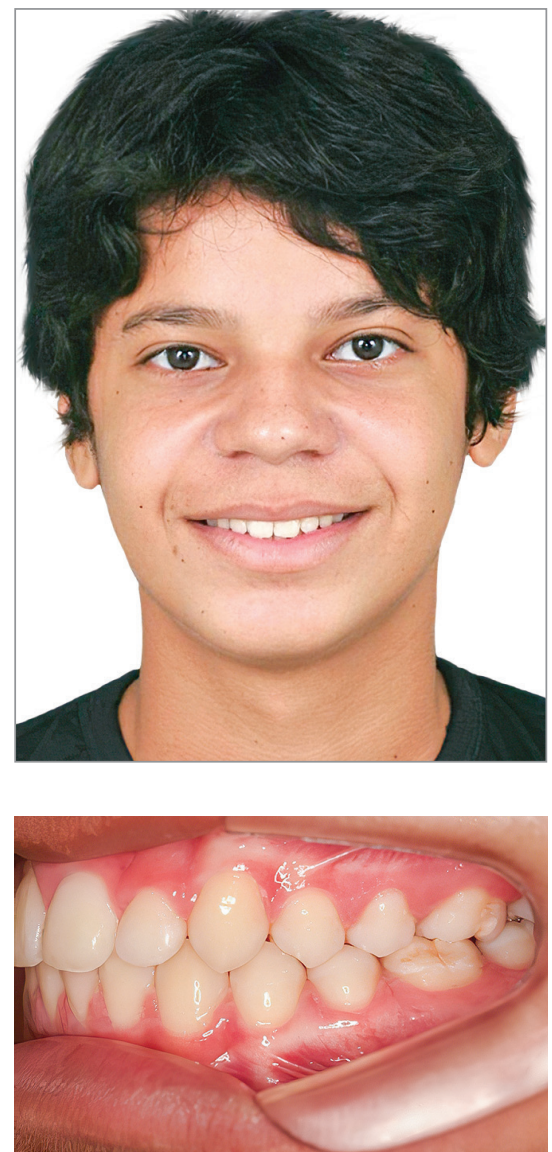

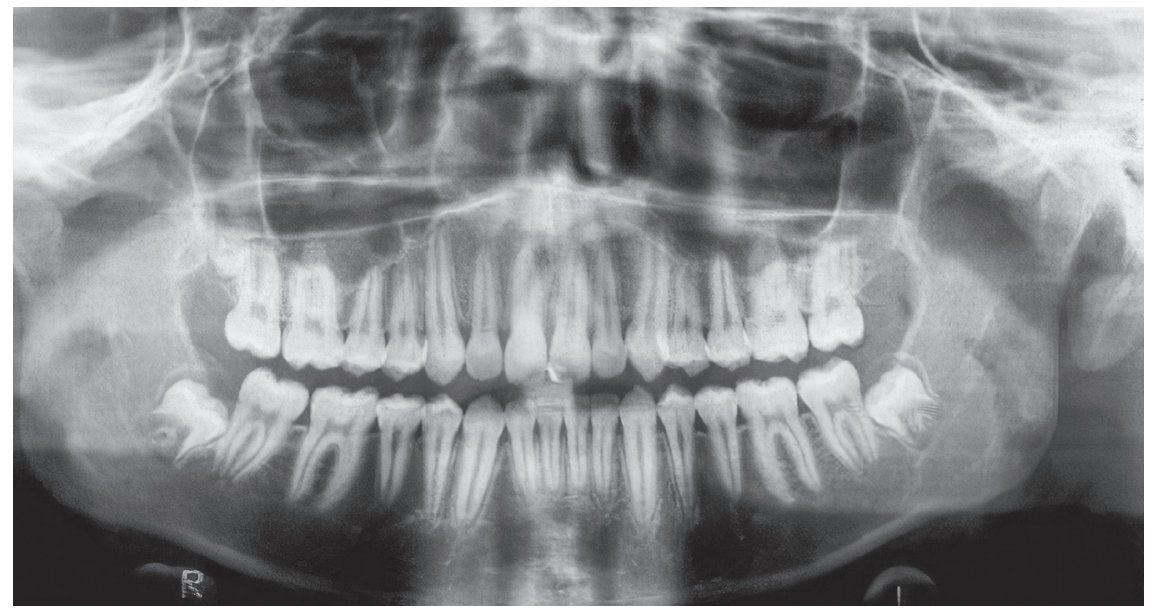



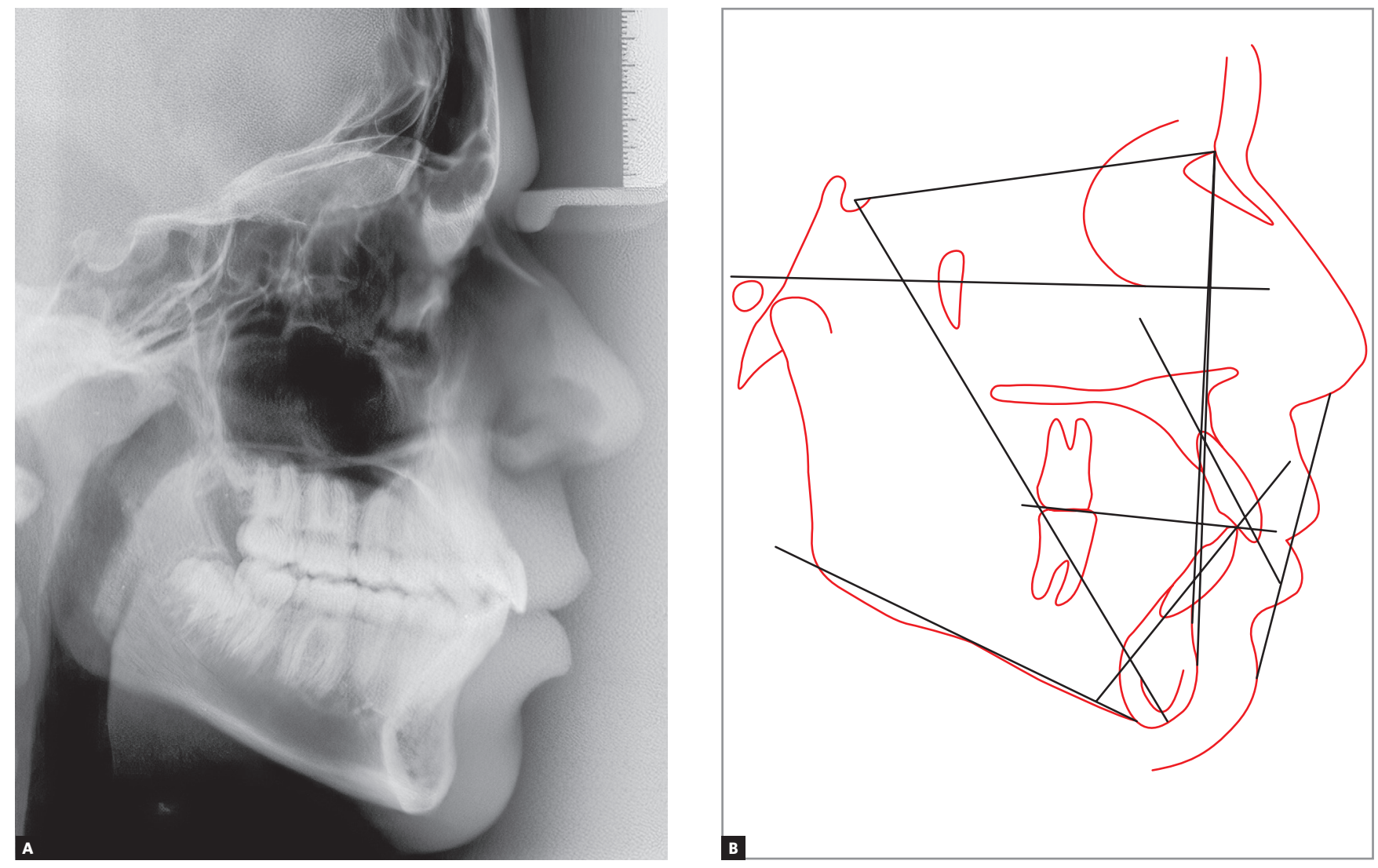

Figure 6 - Final cephalometric radiograph (A) and final cephalometric tracing (B)
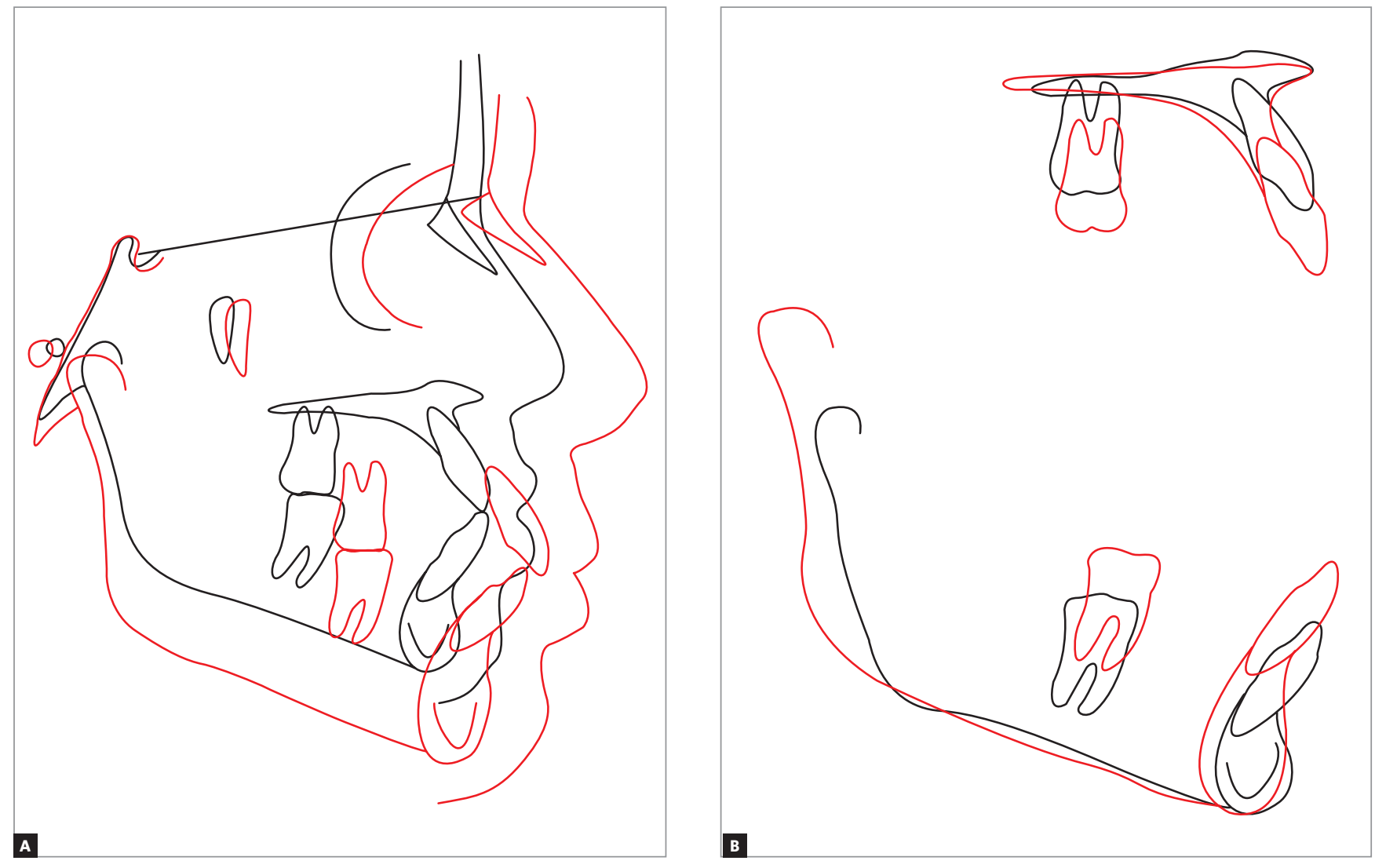

Figure 7 - Total (A) and partial (B) overlays of the initial (black) and final (red) cephalometric tracings. 
Table 1 - Comparison of the initial and final cephalometric measurements of the patient.

\begin{tabular}{|c|c|c|c|c|c|c|}
\hline & Measurement & & Normal & A & B & Dif. $A /$ : \\
\hline \multirow{9}{*}{ Skeletal pattern } & SNA & (Steiner) & $82^{\circ}$ & $80^{\circ}$ & $80^{\circ}$ & 0 \\
\hline & SNB & (Steiner) & $80^{\circ}$ & $82^{\circ}$ & $82^{\circ}$ & 0 \\
\hline & ANB & (Steiner) & $2^{\circ}$ & $0^{\circ}$ & $2^{\circ}$ & 2 \\
\hline & Wits & (Jacobson) & $\begin{array}{l}q 0 \pm 2 \mathrm{~mm} \\
01 \pm 2 \mathrm{~mm}\end{array}$ & $-4 m m$ & $+1 \mathrm{~mm}$ & 5 \\
\hline & Angle of Convexity & (Downs) & $0^{\circ}$ & $0^{\circ}$ & $2^{\circ}$ & 2 \\
\hline & Eixo $Y$ & (Downs) & $59^{\circ}$ & $54^{\circ}$ & $58^{\circ}$ & 4 \\
\hline & Facial Angle & (Downs) & $87^{\circ}$ & $90^{\circ}$ & $88^{\circ}$ & 2 \\
\hline & SN.GoGn & (Steiner) & $32^{\circ}$ & $31^{\circ}$ & $34^{\circ}$ & 3 \\
\hline & FMA & (Tweed) & $25^{\circ}$ & $22^{\circ}$ & $25^{\circ}$ & 3 \\
\hline \multirow{7}{*}{ Dental pattern } & IMPA & (Tweed) & $90^{\circ}$ & $105^{\circ}$ & $102^{\circ}$ & 3 \\
\hline & 1.NA (graus) & (Steiner) & $22^{\circ}$ & $29^{\circ}$ & $27^{\circ}$ & 2 \\
\hline & 1-NA (mm) & (Steiner) & $4 \mathrm{~mm}$ & $6 \mathrm{~mm}$ & $8 \mathrm{~mm}$ & 2 \\
\hline & $\overline{1} . N B$ (graus) & (Steiner) & $25^{\circ}$ & $36^{\circ}$ & $35^{\circ}$ & 1 \\
\hline & $\overline{1}-\mathrm{NB}(\mathrm{mm})$ & (Steiner) & $4 \mathrm{~mm}$ & $8 \mathrm{~mm}$ & $8 \mathrm{~mm}$ & 0 \\
\hline & $\frac{1}{1}$ - Interincisal Angle & (Downs) & $130^{\circ}$ & $114^{\circ}$ & $114^{\circ}$ & 0 \\
\hline & $\overline{1}-\mathrm{APg}$ & (Ricketts) & $1 \mathrm{~mm}$ & $7 \mathrm{~mm}$ & $8 \mathrm{~mm}$ & 1 \\
\hline \multirow{2}{*}{ Profile } & Upper lip-S line & (Steiner) & 0 & $3 \mathrm{~mm}$ & $3 \mathrm{~mm}$ & 0 \\
\hline & Lower lip-S line & (Steiner) & 0 & $5 \mathrm{~mm}$ & $4 \mathrm{~mm}$ & 1 \\
\hline
\end{tabular}

\section{DISCUSSION}

The assessment and treatment of occlusal and skeletal disharmonies can be initiated at various stages of development, depending on the severity, the pattern of skeletal growth, as well as the risks and benefits of treatment itself. Early treatment is definitely a viable possibility; however, it is not indicated for all patients. The objectives of the early orthodontic intervention include controlling unfavorable growth, preventing aggravation of dental and skeletal disharmony, improving occlusion and aesthetics of the smile. Therefore, it is recommended to supervise the development of the occlusion throughout the tooth eruption process in order to offer treatments with more predictable results. In this Class III clinical case, the interceptive approaches to deleterious oral habits together with the early orthopedic treatment of malocclusion, were determining factors for the treatment outcome. ${ }^{11-21}$

Some malocclusions, such as crossbites, do not correct themselves and tend to worsen during the child's growth and development. Therefore, they should be treated as soon as they are diagnosed. There are several reasons for starting treatment in the early stages of mixed dentition: taking advantage of bone bioelasticity; prevent joint disorders; redirect growth towards the normal development of facial and skeletal characteristics; prevent dental disharmonies from evolving to skeletal ones, and improve the breathing pattern in children with mouth breathing or OSAS. In this period, the correction of skeletal changes is simpler and with a lower biological cost for the patient, as in the case of correction of the posterior crossbite by means of disjunction of the median palatal suture. In children aged 8 to 10 years, this palatal suture is wide and with more regular edges, whereas in later periods of growth (10 to 13 years) this suture becomes more irregular and juxtaposed. ${ }^{22}$

The best moment to start treatment in patients with skeletal Class III associated with maxillary retrusion has been widely discussed by studies supported by clinical observations. The periods of primary dentition and the first transitional period of mixed dentition, around 6 years of age, are the most propitious to initiate maxillary protraction, since the orthopedic effects are more expressive, with significant advances in points A and ANS (anterior nasal spine) ${ }^{5,23}$. 
In these periods there is a greater predisposition to anterior displacement of the maxilla, increasing the growth in the maxillary and circummaxillary sutures, which are regular and wide before 8 years of age and become more strongly interdigited near puberty. ${ }^{2}$ In the initial stage of mixed dentition, the best orthopedic responses are observed in the correction of posterior skeletal crossbite, ${ }^{24}$ anterior open bite, ${ }^{25}$ and skeletal Class III. ${ }^{1}$

The therapeutic decisions made for the first phase guaranteed the results obtained at the end of the entire treatment. The indication of lingual spurs is presented in the literature as a valid therapeutic modality to eliminate the habit of interposing and reeducating the tongue posture, contributing to the correction of the anterior open bite. ${ }^{11,15,26-30}$ For this reason, immediately after the disjunction of the maxilla, the lingual arch with welded spurs was installed. So that, without the interference of the tongue, the correction of the anterior open bite occurred simultaneously with the effects of the treatment with the facemask that redirected the maxillary growth forward and down.

The decision for maxillary protraction was based on evidence proven by literature that the Class III treatment with the facemask is the most widely chosen for the correction of the retrognathic maxilla. ${ }^{13,17}$ Studies show significant favorable results in the correction of dental and skeletal variables, such as positive changes in the Wits analysis indexes and in the correction of the patient's overjet., ${ }^{5,17,31}$ These previously reported characteristics corroborate the results of this clinical case, which culminated in the improvement of Wits analysis values from $-4 \mathrm{~mm}$ pretreatment to $+1 \mathrm{~mm}$ after treatment, and adequate overjet and overbite.

The protocols adopted for maxillary protraction of this patient are also in accordance with those stated by the scientific literature, such as previous maxillary disjunction ${ }^{5,17,31-33}$ followed by protraction of the maxilla with an approximate direction of $30^{\circ}$ downwards and forwards, and magnitude of force between $300 \mathrm{gF}$ and $600 \mathrm{gF}$ per activation side..$^{5,31-35}$ This first phase of treatment promoted a more favorable environment for the expression of facial growth and development, correcting occlusal relationships, improving facial aesthetics and self-esteem, and minimizing permanent skeletal deformations in the adult phase. ${ }^{19}$
Therefore, the treatment of Class III performed during the growth period promoted positive results. However, the hereditary character of this malocclusion can compromise the results obtained with early treatment, making more invasive treatments such as orthognathic surgeries necessary, if the patient is not properly monitored orthodontically until the end of his growth. Thus, it is important that the treatment of Class III is carried out in two stages, the first stage of interception, with orthopedic and functional treatment, and the second stage, of orthodontic treatment with fixed appliances, for the refinement of occlusal relationships, with use of Class III intermaxillary elastics for the consolidation of Class I obtained after maxillary protraction therapy. ${ }^{17}$

\section{CONCLUSION}

The intervention and supervision of skeletal Class III performed in patients before the growth spurt, associated with the interception of deleterious oral habits and effective and efficient orthodontic mechanics are decisive factors for the success of orthodontic treatment of this malocclusion.

\section{Authors' contribution (ORCID ${ }^{(\mathbb{D})}$}

Dennyson B. H. S. (DBHS): 0000-0002-9831-0239

Ariane Salgado Gonzaga (ASG): 0000-0002-1012-4803 (D)

Conception or design of the study: DBHS, ASG. Data acquisition, analysis or interpretation: DBHS, ASG. Writing the article: ASG. Critical revision of the article: DBHS, ASG. Final approval of the article: DBHS, ASG. 


\section{REFERENCES}

1. Ngan P. Early timely treatment of Class III malocclusion. Semin Orthod. 2005; 11:140-5

2. Ngan P, Alkire RG, Fields Jr H. Management of space problems in the primary and mixed dentitions. J Am Dent Assoc. 1999 Sept;130(9):1330-9.

3. Araújo EA, Buschang PH. Recognizing and correcting developing malocclusions: a problem-oriented approach to orthodontics. New Jersey: Wiley Brackwell; 2016. p. 255.

4. de Almeida MR, de Almeida RR, Oltramari-Navarro PVP, Conti ACCF, Navarro RL, Camacho JGDD. Early treatment of Class III malocclusion 10-year clinical follow-up. J Appl Oral Sci. 2011 Aug;19(4):431-9.

5. Mandall N, Cousley R, DiBiase A, Dyer F, Littlewood S, Mattick R, et al. Early Class III protraction facemask treatment reduces the need for orthognathic surgery: a multi-centre, two-arm parallel randomized, controlled trial. J Orthod. 2016 Sept;43(3):164-75.

6. Nardoni DN, Siqueira DF, Cardoso MA, Capelozza Filho L. Cephalometric variables used to predict the success of interceptive treatment with rapid maxillary expansion and face mask. A longitudinal study. Dental Press J Orthod. 2015 Jan-Feb;20(1):85-96.

7. Clemente R, Contardo L, Greco C, Di Lenarda R, Perinetti G. Class III treatment with skeletal and dental anchorage: a review of comparative effects. Biomed Res Int. 2018 July 2;2018:7946019.

8. Pisani L, Bonaccorso L, Fastuca R, Spena R, Lombardo L, Caprioglio A. Systematic review for orthodontic and orthopedic treatments for anterior open bite in the mixed dentition. Prog Orthod. 2016 Dec:17(1):28.

9. Fialho MPN, Pinzan-Vercelino CRM, Nogueira RP, Gurgel JA. Relationship between facial morphology, anterior open bite and non-nutritive sucking habits during the primary dentition stage. Dental Press J Orthod. 2014 May-June;19(3):108-13

10. Jacobson A. The "Wits" appraisal of jaw disharmony. Am J Orthod Dentofacial Orthop. 2003 Nov;124(5):470-9

11. Cassis MA, de Almeida RR, Janson G, Aliaga-Del Castillo A, de Almeida MR. Stability of anterior open bite treatment with bonded spurs associated with high- pull chincup. Orthod Craniofac Res. 2018 May:21(2):104-11

12. Ngan P, Fields HW. Open bite: a review of etiology and management. Pediatr Dent. 1997 Mar-Apr:19(2):91-8.

13. Watkinson S, Harrison JE, Furness S, Worthington HV. Orthodontic treatment for prominent lower front teeth (Class III malocclusion) in children. Cochrane Database Syst Rev. 2013 Sept;30(9):CD003451

14. Cozza P, Baccetti T. Fanchi L, Mucedero M, Polimeni A. Sucking habits and facial hyperdivergency as risk factors for anterior open bite in the mixed dentition. Am J Orthod Dentofacial Orthop. 2005 Oct:128(4):517-9

15. Nascimento MHA, de Araújo TM, Machado AW. Severe anterior open bite during mixed dentition treated with palatal spurs. J Clin Pediatr Dent. 2016:40(3):247-50.

16. Heimer MV, Katz CRT, Rosenblatt A. Anterior open bite: a case - control study. Int J Paediatr Dent. 2010 Jan;20(1):59-64

17. Woon SC, Thiruvenkatachari B. Early orthodontic treatment for Class III malocclusion: a systematic review and meta-analysis. Am J Orthod Dentofacial Orthop. 2017 Jan;151(1):28-52.

18. Baccetti T, Tollaro I. A retrospective comparison of functional appliance treatment of Class III malocclusions in the deciduous and mixed dentitions. Eur J Orthod. 1998 June:20(3):309-17.

19. Campbell PM. The dilemma of Class III treatment. Early or late? Angle Orthod. 1983 July:53(3):175-91
20. Kapust AJ, Sinclair PM, Turley PK. Cephalometric effects of face mask/ expansion therapy in Class III children: a comparison of three age groups. Am J Orthod Dentofacial Orthop. 1998 Feb;113(2):204-12.

21. Atalay $Z$, Tortop T. Dentofacial effects of a modified tandem traction bow appliance. Eur J Orthod. 2010 Dec;32(6):655-61.

22. Melsen B, Melsen $\mathrm{F}$ The postnatal development of the palatomaxillary region studied on human autopsy material. Am J Orthod. 1982 Oct; 82(4):329-42

23. Mandall N, DiBiase A, Littlewood S, Nute S, Stivaros N, McDowall R, et al. Is early Class III protraction facemask treatment effective? A multicentre, randomized, controlled trial: 15-month follow-up. J Orthod. 2010 Sept; 37(3):149-61

24. Ugolini A, Cerruto C, Di Vece L, Ghislanzoni LH, Sforza C, Doldo T, et al Dental arch response to Haas-type rapid maxillary expansion anchored to deciduous vs permanent molars: a multicentric randomized controlled trial. Angle Orthod. 2015 July:85(4):570-6

25. Rédua RB. Different approaches to the treatment of skeletal Class II malocclusion during growth: Bionator versus extraoral appliance Dental Press J Orthod. 2020 Mar-Apr;25(2):69-85

26. Justus R. Correction of anterior open bite with spurs: long-term stability. World J Orthod. 2001:2(3):219-31.

27. Meyer-Marcotty P, Hartmann J, Stellzig-Eisenhauer A. Dentoalveolar open bite treatment with spur appliances. J Orofac Orthop. 2007 Nov:68(6):510-21.

28. Cassis MA, de Almeida RR, Janson G, de Almeida-Pedrin RR, de Almeida MR. Treatment effects of bonded spurs associated with high-pull chincup therapy in the treatment of patients with anterior open bite. Am J Orthod Dentofacial Orthop. 2012 Oct;142(4):487-93.

29. Leite JS, Matiussi LB, Salem AC, Provenzano MGA, Ramos AL. Effects of palatal crib and bonded spurs in early treatment of anterior open bite: a prospective randomized clinical study. Angle Orthod. 2016 Sept:86(5):734-9.

30. Canuto LFG, Janson G, de Lima NS, de Almeida RR, Cançado RH Anterior open-bite treatment with bonded vs conventional lingual spurs: a comparative study. Am J Orthod Dentofacial Orthop. 2016 June;149(6):847-55

31. Liu W, Zhou Y, Wang X, Liu D, Zhou S. Effect of maxillary protraction with alternating rapid palatal expansion and constriction vs expansion alone in maxillary retrusive patients: a single-center, randomized controlled trial. Am J Orthod Dentofacial Orthop. 2015 Oct;148(4):641-51.

32. Keles A, Tokmak EC, Erverdi N, Nanda R. Effect of varying the force direction on maxillary orthopedic protraction. Angle Orthod. 2002 Oct;72(5):387-96

33. Vaughn GA, Mason B, Moon HB, Turley PK. The effects of maxillary protraction therapy with or without rapid palatal expansion a prospective, randomized clinical trial. Am J Orthod Dentofacial Orthop. 2005 Sept;128(3):299-309

34. Cozza P, Baccetti T, Mucedero M, Pavoni C, Franchi L. Treatment and posttreatment effects of a facial mask combined with a bite-block appliance in Class III malocclusion. Am J Orthod Dentofacial Orthop. 2010 Sept:138(3):300-10

35. Cozza P, Marino A, Mucedero M. An orthopaedic approach to the treatment of Class III malocclusions in the early mixed dentition. Eur J Orthod. 2004 Apr:26(2):191-9. 